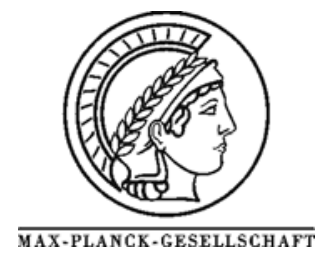

\title{
Oxidation of methanol on Ru catalyst: Effect of the reagents partial pressures on the catalyst oxidation state and selectivity
}

\author{
R. Blume ${ }^{\text {a }}$, M. Hävecker ${ }^{\text {a }}$ S. Zafeiratos ${ }^{\text {a }}$ D. Teschner ${ }^{\text {a }}$, A. Knop-Gericke ${ }^{\text {a }}$, \\ R. Schlögl ${ }^{\text {a }}$ P. Dudin ${ }^{\text {b }}$, A. Barinov ${ }^{\text {b }}$, M. Kiskinova ${ }^{\text {b* }}$ \\ ${ }^{a}$ Fritz-Haber-Institut der Max-Planck-Gesellschaft, Faradayweg 4-6, 14195 Berlin, Germany \\ ${ }^{\mathrm{b}}$ Sincrotrone Trieste, AREA Science Park, Basovizza, Trieste 34012, Italy \\ *Corresponding author: e-mail Maya.Kiskinova@elettra.trieste.it,
}

Available online 2. April 2007.

\begin{abstract}
In situ core level photoelectron spectroscopy and mass spectrometry have been utilized to study the methanol oxidation on a model RuO2 catalyst at pressures ranging from $10^{-6}$ to $10^{-1}$ mbar. The experiments were carried out varying the $\mathrm{O}_{2} / \mathrm{CH}_{3} \mathrm{OH}$ molecular mixing ratio from 0.25 to 3.3 and the reaction temperature from 350 to $720 \mathrm{~K}$. The $\mathrm{Ru} 3 \mathrm{~d}_{5 / 2}$ and $\mathrm{O} 1$ s core level spectra were used to characterise the dynamic changes in the Ru oxidation state by exposing the oxide pre-catalyst to different reagents partial pressures and temperatures. Full oxidation to $\mathrm{CO}_{2}+\mathrm{H}_{2} \mathrm{O}$ or partial oxidation to $\mathrm{CO}+\mathrm{H}_{2} \mathrm{O}+\mathrm{H}_{2}$ have been observed in the whole pressure range for specific reaction conditions, which preserve the oxide catalyst state or reduce the oxide to metallic Ru. The selective oxidation to formaldehyde is observed only at pressures in the $10^{-1}$ mbar range, catalyzed by a RuOx surface oxide formed by partial reduction of the oxide pre-catalyst.
\end{abstract}

Keywords: Ruthenium; Methanol; Oxidation; Formaldehyde; High-pressure XPS; Mass-spectrometry

\section{Introduction}

The catalytically active state under reaction conditions is still a very disputable issue. In the particular cases of oxidation reactions the classical oxygen source considered in modelling the reactions mechanism is the lattice oxygen on nearly stoichiometric surfaces of metal oxides (Mars-van Krevelen mechanism) [1], or adsorbed oxygen on metal surfaces. In both cases, the consumed surface oxygen is restored by the $\mathrm{O}_{2}$ reactant in the gas phase.

In reality, the catalytically active state is not necessarily the well-defined oxide phase, and possible differences in the socalled 'oxidation state' of the surface and the bulk have already been considered [2]. Studies of selective oxidation of $\mathrm{CH}_{3} \mathrm{OH}$ on $\mathrm{Cu}$ have provided clear evidence for catalytically active state with incorporated subsurface oxygen, which can be described as a disordered surface oxide film [3,4]. Such surface oxide states are in fact the transient precursors towards formation of metal bulk oxides, which nucleate and grow when a critical amount of oxygen is incorporated subsurface [5]. The calculated temperature-pressure $\left(\mathrm{T}, \mathrm{P}_{\mathrm{O} 2}\right)$ phase diagrams attempting to predict the thermodynamically stable phases under realistic oxidation conditions confirm that the oxidation of transition metals is a rather complex process with phase coexistence regions [6-8]. In realistic oxidation reactions the second reactant usually acts as a reducer (e.g. $\mathrm{CO}, \mathrm{H}_{2}, \mathrm{CH}_{3} \mathrm{OH}$ or other organic molecules) and affects the $\left(\mathrm{T}, \mathrm{P}_{\mathrm{O} 2}\right)$ space of oxidation phases driving the oxidation state away from the equilibrium achieved in a pure $\mathrm{O}_{2}$ ambient. Consequently, when the reactions have several possible pathways the selectivity and the corresponding catalytically active state can be controlled by varying the reaction temperature and chemical potentials (partial pressures) of the reactants.

In the last decade a main challenge of the surface science UHVexperiments is that often enough the extensive knowledge about important elementary processes at the model catalyst's surface cannot be directly extrapolated to the catalytic processes occurring at ambient pressures, when the chemical potentials of reagents in the gas phase become important. In this respect $\mathrm{Ru}$, a catalyst used in exhaust gas converters and fuel cells is a textbook example of the so-called 'pressure gap' in oxidation and catalyst activity. Under UHV conditions the Ru catalyst turned out 
to be completely inactive for CO oxidation due to the kinetic limitation for accumulation of oxygen to form the catalytically active surface at the low oxygen potentials in the traditional surface science experiments [9-11]. The crucial role of the PO2 became apparent in a number of recent investigations showing that it is a prerequisite for formation of the catalytically active phases, namely a thin surface oxide film (RuOx) at $\mathrm{T}<550 \mathrm{~K}$ and a stoichiometric well-ordered RuO2( 110 ) phase at $\mathrm{T}>550 \mathrm{~K}[10,12-$ 14]. Extensive structural, photoemission and TPD studies characterized the lower temperature Ru oxidation state as a disordered RuOx with 1-4 ML oxygen incorporated within the top few Ru layers, which also precedes the nucleation and growth of the stoichiometric $\mathrm{RuO} 2$ phase at higher temperatures [14]. They have also provided evidence for the coexistence of RuOx with the $\mathrm{RuO} 2$ phase in a wide $(\mathrm{T}$, $\mathrm{PO} 2$ ) range.

One of the approaches to narrowing the pressure gap, used in our previous study of $\mathrm{CO}$ oxidation on a $\mathrm{Ru}(0001)$ catalyst, is monitoring the catalytically active state and products in the gas phase by in situ mbar-bar pressure Xray photoemission spectroscopy (XPS) and massspectrometry [3]. We found that below $500 \mathrm{~K}$, when the formation of $\mathrm{RuO}_{2}$ is kinetically hindered, the surface is already activated for $\mathrm{CO}$ oxidation by formation of the precursor surface oxide, RuOx [15]. The actual surface state of the catalyst dynamically changed with temperature and $\mathrm{CO} / \mathrm{O}_{2}$ partial pressures. Both the $\mathrm{RuOx}$ 'surface oxide' and $\mathrm{RuO}_{2}$ states can easily be reduced into an inactive $\mathrm{Ru}$ metal with adsorbed oxygen in excess of $\mathrm{CO}$ and $\mathrm{Ru}$ can be re-oxidised in an excess of oxygen regaining the catalytic activity. The active role of subsurface oxygen and formation of surface oxide RuOx have also been considered in catalytic behaviour of Ru electrodes in fuel cells [16,17].

The CO oxidation is a simple single-channel reaction system, which cannot tackle the 'pressure gap' in catalyst selectivity, another very important issue addressed by the present study of $\mathrm{CH}_{3} \mathrm{OH}$ oxidation on a model $\mathrm{Ru}(0001)$ catalyst. $\mathrm{CH}_{3} \mathrm{OH}$ catalytic oxidation is a complex process with long list of possible reactions involving different intermediates and final products, which also depend on the catalyst chemical state $[18,19]$. The first common step on both metal and oxide surfaces is $\mathrm{H}$ abstraction, yielding $\mathrm{H}_{\mathrm{s}}$ or $\mathrm{OH}_{\mathrm{s}}$ and methoxy, $\mathrm{CH}_{3} \mathrm{Os}$, where the subscript ' $\mathrm{s}$ ' indicates that the species is bonded at the surface. In the presence of oxygen further activation of the $\mathrm{C}-\mathrm{H}$ bonds in $\mathrm{CH}_{3} \mathrm{O}_{\mathrm{s}}$ through red-ox cycles leading to $\mathrm{H}_{2}, \mathrm{CH}_{2} \mathrm{O}, \mathrm{CO}$, $\mathrm{CO}_{2}$ and $\mathrm{H}_{2} \mathrm{O}$ (products of partial or complete oxidation), passes through the following principle intermediates: $\mathrm{OH}_{\mathrm{s}}$, $\mathrm{H}_{\mathrm{s}}, \mathrm{CH}_{\mathrm{x}} \mathrm{O}_{\mathrm{s}}, \mathrm{CO}_{\mathrm{s}}$ and $\mathrm{HCOO}_{\mathrm{s}}$. The $\mathrm{CO}_{2}$ can result of decomposition of the $\mathrm{HCOO}_{\mathrm{s}}$ or secondary oxidation reaction of $\mathrm{CO}_{\mathrm{s}}$. Starting with an oxidised $\mathrm{Ru}(0001)$ catalyst, considered to be the catalytic active state for $\mathrm{CH}_{3} \mathrm{OH}$ oxidativedehydrogenation to $\mathrm{CH}_{2} \mathrm{O}+\mathrm{H}_{2} \mathrm{O}$ [20], we followed in real time the products yield and the evolution of $\mathrm{Ru}$ oxidation state and adlayer in the $10^{-6}$ to $10^{-1}$ mbar range varying the $\left(\mathrm{T}, \mathrm{PO}_{2}, \mathrm{PCH}_{3} \mathrm{OH}\right)$ space.

\section{Experimental}

The experiments were performed at the synchrotron radiation facility BESSY in Berlin in the high pressure XPS station designed and constructed in the FHI-MPG [21]. The sample, mounted inside a reaction cell, $2 \mathrm{~mm}$ away from the entrance aperture to the differentially pumped hemispherical analyser Phoibos 150 (SPECS GmbH), was heated from the backside using an infrared laser system. The $\mathrm{CH}_{3} \mathrm{OH}$ and $\mathrm{O}_{2}$ gas flows and the products released in the gas phase were monitored by a Hiden mass spectrometer. The fragmentation patterns of the reactants and products and the sensitivity factors were considered in the determination the molecular mixing ratio of the reagents and the relative yield of the products. In particular, this concerns the $\mathrm{CH}_{2} \mathrm{O}$ and $\mathrm{CO}$ yields, which should be corrected for the attenuation of the $\mathrm{CH}_{3} \mathrm{OH}$-related mass signals 30 and 28 due to $\mathrm{CH}_{3} \mathrm{OH}$ consumption. The relative decrease of the mass 31 was used as a measure of the methanol conversion. The $\mathrm{Ru}(0001)$ sample was cleaned before each reaction cycle using the well established procedures [12,22] and then oxidised to form a $\mathrm{RuO}_{2}$ phase with thickness of 5-10 nm. All photoelectron spectra were normalized to the photon flux, monitored by a photodiode. The $\mathrm{Ru} 3 \mathrm{~d}$ and $\mathrm{O}$ 1s spectra were measured in normal emission with photon energies of 450 and $650 \mathrm{eV}$, respectively and overall spectral resolution of $0.3 \mathrm{eV}$. According to the universal curve for the electron mean free path [23] the effective escape depths for the $\mathrm{O} 1 \mathrm{~s}$ and $\mathrm{Ru} 3 \mathrm{~d}$ photoelectrons is $\sim 5 \AA$, which limits the probing depth to the top few layers ( $10 \AA)$.

The dynamic response of the $\mathrm{O} 1 \mathrm{~s}$ and $\mathrm{Ru} 3 \mathrm{~d}_{5 / 2}$ core level spectra was used for precise assignment of the catalyst oxidation state, which was correlated to the corresponding yields of the products of methanol oxidation. $\mathrm{CO}, \mathrm{CO}_{2}, \mathrm{H}_{2}$, $\mathrm{H}_{2} \mathrm{O}$ and $\mathrm{CH}_{2} \mathrm{O}$, detected with the mass spectrometer in our experiments. The already available $\mathrm{Ru} 3 \mathrm{~d}_{5 / 2}$ and $\mathrm{O} 1$ s core level spectroscopy data provided the necessary basis for identification of the $\mathrm{Ru}$ oxidation states (metallic $\mathrm{Ru}$ with adsorbed oxygen, $\mathrm{RuOx}$ 'surface oxide', and $\mathrm{RuO}_{2}$ ) and the ad-species (see Table 1). For the Ru(0001) surface the intensity ratio between the overlapping O-related $\mathrm{Ru} 3 \mathrm{~d}_{5 / 2}$ component at 280.5-280.6 eV, accounting for both adsorbed oxygen and $\mathrm{RuOx}$ and the bulk component, $\mathrm{Ru}_{\text {bulk, }}$, turned out to be the best fingerprint for differentiation between adsorption oxygen state with coverage 0.33-0.67 ML on Ru(0001) and RuOx. For the RuOx state, detected under our experimental conditions this ratio was significantly higher for than the characteristic ratio of 0.3 for 0.67 ML of adsorbed oxygen and reaches $\sim 0.6$ for $\sim 4$ ML incorporated oxygen. The $\mathrm{Ru} 3 \mathrm{~d}_{5 / 2}$ and $\mathrm{O} 1$ s spectra of the initial oxide pre-catalyst, prepared by in situ oxidation of $\mathrm{Ru}(0001)$ at $720 \mathrm{~K}$ and $10^{-1}<\mathrm{P}_{\mathrm{O} 2}<1$ mbar contained only the characteristic features of the $\mathrm{RuO} 2$ at 280.75 and 529.5 $\mathrm{eV}$, respectively. 

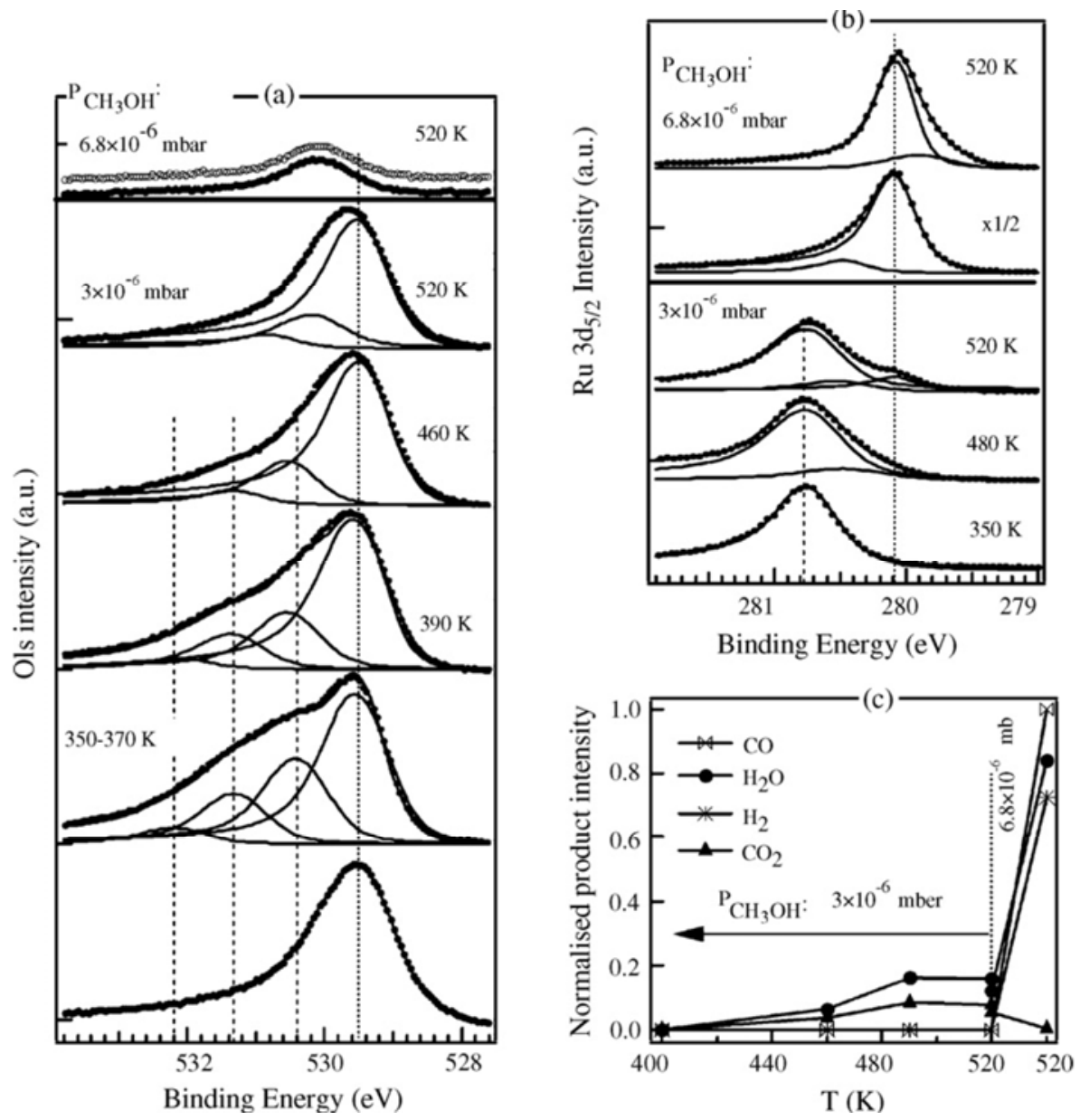

Fig. 1: O 1s (a) and Ru 3d $d_{5 / 2}$ (b) spectra taken at different temperatures for two different MR: 0.6 (bottom panel) and 0.25 (top panel). The bottom spectra in (a) and (b) represent the oxide pre-catalyst before introducing $\mathrm{CH} 3 \mathrm{OH}$ in the gas phase. In (a) the dashed lines from left to right indicate the O 1s components assigned to CH2Os (_532.2), CH3Os (_531.5) and OHs (_530.5) and the dotted line indicates the oxide component. In (b) the dashed and dotted lines denote RuO2 and the Rubulk components. (c) Mass spectra normalized intensity of reaction products as a function of temperature and the changes occurring in products yield at $520 \mathrm{~K}$ after decreasing the MMR from 0.6 to 0.25 . The dashed line divides the parts of different PCH3OH. PO2 was kept constant, $1.7 \_10 \_6$ mbar.

Table 1: Reported $\mathrm{Ru}_{5 / 2}$ and $\mathrm{O}$ 1s binding energies of different chemical state of Ru and of some adsorbed species relevant to the present study

\begin{tabular}{|c|c|c|c|}
\hline Core level & $\begin{array}{l}\text { Binding energy } \\
( \pm 0.05 \mathrm{eV})\end{array}$ & Component identity & References \\
\hline $\mathrm{Ru} 3 \mathrm{~d}_{5 / 2}$ & 280.1 & $\mathrm{Ru}(0000$ 1)-bulk & {$[22,24]$} \\
\hline $\operatorname{Ru} 3 \mathrm{~d}_{5 / 2^{-}}$ & 279.75 & $\operatorname{Ru}\left(\begin{array}{llll}0 & 0 & 0 & 1\end{array}\right)$-surface & \\
\hline $\mathrm{Ru} 3 \mathrm{~d}_{5 / 2}$ & 280.75 & $\mathrm{RuO}_{2}$ & [25] \\
\hline $\mathrm{Ru} 3 \mathrm{~d}_{5 / 2}$ & $\begin{array}{l}280.1,280.5,281.0 \\
280.5-280.6\end{array}$ & $\begin{array}{l}\mathrm{Ru}-\mathrm{O}_{\mathrm{ad}}, \mathrm{Ru}-2 \mathrm{O}_{\mathrm{ad}}, \mathrm{Ru}-3 \mathrm{O} \text { ad } \\
\mathrm{RuO}_{x}\end{array}$ & $\begin{array}{l}{[22]} \\
{[14]}\end{array}$ \\
\hline $\mathrm{O}$ 1s & 530.0 & $\mathrm{O}_{\mathrm{ad}}$ and $\mathrm{RuO}_{x}$ & {$[14,22]$} \\
\hline $\mathrm{O}$ is & 529.5 & $\mathrm{O}$ in $\mathrm{RuO}_{2}$ & [25] \\
\hline $\mathrm{O}$ 1s & 530.4 & $\mathrm{OH}_{5}$ on $\mathrm{RuO}_{2}$ & [26] \\
\hline $\mathrm{O}$ is & 531.2 & $\mathrm{CH}_{3} \mathrm{O}_{5}$ on $\mathrm{RuO}_{2}$ & [26] \\
\hline $\mathrm{O}$ is & 532.2 & $\mathrm{CH}_{2} \mathrm{O}_{5}$ on $\mathrm{RuO}_{2}$ & [26] \\
\hline $\mathrm{O}$ is & $532.8-533.3$ & $\mathrm{CH}_{3} \mathrm{OH}_{\mathrm{s}}$ on metals & [27] \\
\hline $\mathrm{O}$ 1s & $530.6-531.9$ & $\mathrm{CO}_{s}$ on $\mathrm{Ru}$ & {$[28,29]$} \\
\hline
\end{tabular}

\section{Results}

The evolution of the catalyst chemical state and adlayer composition and the corresponding catalyst activity were studied for different temperatures and partial pressures of $\mathrm{O} 2$ and $\mathrm{CH} 3 \mathrm{OH}$ in the $10 \_6$ to $10 \_1$ mbar range. Most of the experiments were carried out at oxygen potentials supposed to favour partial oxidation reactions, particularly focused on the selective oxidative dehydrogenation to formaldehyde, the product of industrial importance. As reported below sensible formaldehyde production was monitored only in the 10_1 mbar range and conditions for high selectivity were obtained at $\mathrm{T}>450 \mathrm{~K}$ for $\mathrm{O} 2 / \mathrm{CH} 3 \mathrm{OH}$ molecular mixing ratio (MMR) of 0.6. Since it is nar"ve to narrow the pressure gap by maintaining a constant $\mathrm{O} 2 / \mathrm{CH} 3 \mathrm{OH}$ partial pressure ratio experiments varying the MMR were performed as well. 

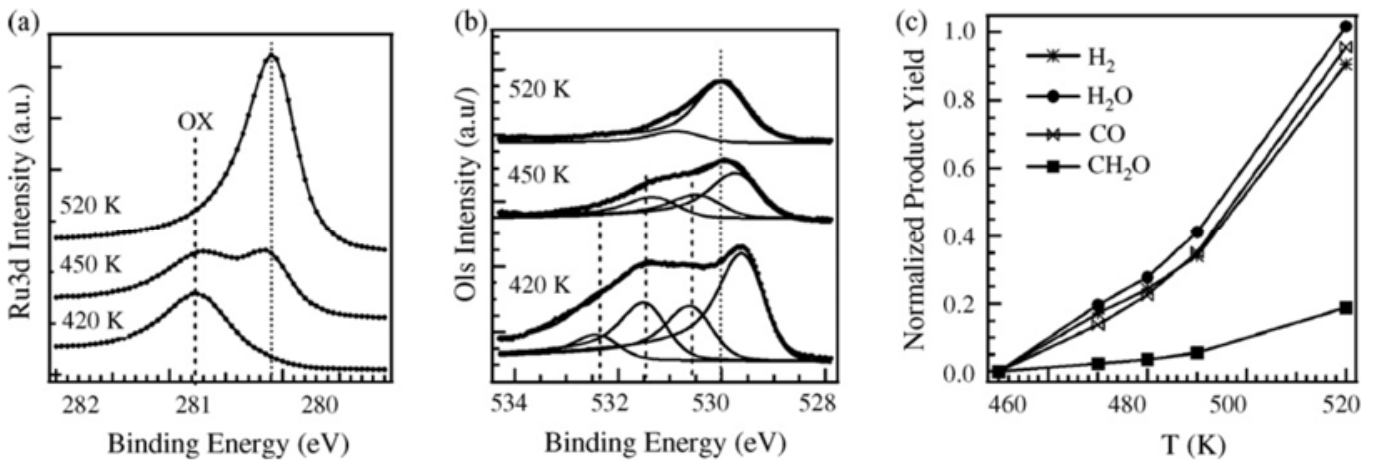

Fig. 2: $\mathrm{Ru} 3 \mathrm{~d}_{5 / 2}$ (a) and $\mathrm{O} 1 \mathrm{~s}$ (b) spectra corresponding to different reaction temperature for MMR of 0.3 at $\mathrm{P}_{\text {total }}=1.8 \times 10^{-1} \mathrm{mbar}$. In (a) and dotted lines indicate oxide and bulk metallic Ru component. In (b) the dashed lines from left to right indicate the $\mathrm{O} 1 \mathrm{~s}$ energy positions of $\mathrm{CH}_{2} \mathrm{O}_{\mathrm{s}}$, $\mathrm{CH}_{3} \mathrm{O}_{\mathrm{s}}$ and $\mathrm{OH}_{\mathrm{s}}$ or $\mathrm{CO}_{\mathrm{s}}$ and the dotted line indicates the component of adsorbed oxygen. (c) Mass spectra normalized intensity of reaction products as a function of temperature

Fig. 1(a and b) shows the $\mathrm{O} 1 \mathrm{~s}$ and $\mathrm{Ru} 3 \mathrm{~d}_{5 / 2}$ spectra of the oxidised pre-catalyst in the $10^{-6}$ mbar range measured at different temperatures for MMR of 0.6 and following decrease of MMR to 0.25 at $520 \mathrm{~K}$. The $\mathrm{O} 1 \mathrm{~s}$ and $\mathrm{Ru} 3 \mathrm{~d}_{5 / 2}$ spectra before exposure to the reactants mixture correspond to the $\mathrm{RuO}_{2}$ state (peaked at_529.5 and $280.8 \mathrm{eV}$ ). The $\mathrm{O}$ $1 \mathrm{~s}$ spectrum undergoes significant changes after introducing the $\mathrm{CH}_{3} \mathrm{OH}$ reactant. The broad multi-component feature growing on the high-energy side of the $\mathrm{O}$ 1s spectra results from the $\mathrm{OH}_{\mathrm{s}}$ and $\mathrm{CH}_{\mathrm{x}} \mathrm{O}_{\mathrm{s}}$ ad-species, derived from $\mathrm{CH}_{3} \mathrm{OH}$ dissociative adsorption. The $\mathrm{O} 1 \mathrm{~s}$ components giving the best fit of the $\mathrm{O}$ 1s spectra in Fig. 1(a) are in fair agreement with the binding energies of $\mathrm{OH}_{\mathrm{s}}, \mathrm{CH}_{3} \mathrm{O}_{\mathrm{s}}$ and $\mathrm{CH}_{2} \mathrm{O}_{\mathrm{s}}$ species on a $\mathrm{RuO}_{2}(110)$ surface (see Table 1). The attenuation and extinction of these $\mathrm{O} 1$ s components in the 390-500 K range mark desorption of the $\mathrm{CH}_{3} \mathrm{OH}$-related ad-species. The small shift of the component assigned to $\mathrm{OH}_{\mathrm{s}}$ at 390 and $460 \mathrm{~K}$ may be due to overlap with the emerging $\mathrm{CO}_{\mathrm{s}}$ component resulting from further dehydrogenation of $\mathrm{CH}_{\mathrm{x}} \mathrm{O}_{\mathrm{s}}$ species. At MMR $=0.6$ the oxide catalyst state is preserved up to temperatures of $\sim 470 \mathrm{~K}$. At $480 \mathrm{~K}$ the measured $\mathrm{Ru} 3 \mathrm{~d}_{5 / 2}$ spectrum is still dominated by the $\mathrm{RuO}_{2}$ component but it starts to broaden on the low energy side due to the emergence of a component at $\sim 280.5$ $\mathrm{eV}$ of the partially reduced RuOx phase. Above this temperature the $\mathrm{Ru}$ bulk component also emerges in the $\mathrm{Ru}$ $3 \mathrm{~d}_{5 / 2}$ spectra indicating sensible partial reduction of $\mathrm{RuO}_{2}$. The presence of $\mathrm{RuO}_{2}$ and $\mathrm{RuOx}$ components in the $\mathrm{Ru}$ $3 \mathrm{~d}_{5 / 2}$ spectrum at $520 \mathrm{~K}$ indicates that both phases coexist at this $\mathrm{T}, \mathrm{P}_{\mathrm{O} 2}, \mathrm{P}_{\mathrm{CH} 3 \mathrm{OH}}$ space, the fraction of the $\mathrm{RuO}_{2}$ surface being still dominant. At $\mathrm{T} \sim 460-480 \mathrm{~K}$ the components of the $\mathrm{CH}_{3} \mathrm{OH}$-related almost disappear and the $\mathrm{O} 1 \mathrm{~s}$ spectra at $520 \mathrm{~K}$ have components corresponding to oxide, $\mathrm{RuOx}$ and the weakest component at $\sim 531 \mathrm{eV}$ is most likely $\mathrm{CO}_{\mathrm{s}}$. At $\mathrm{T} \geq 450 \mathrm{~K}$ small $\mathrm{CO}_{2}$ and $\mathrm{H}_{2} \mathrm{O}$ production with almost constant yields in the $\sim 490-520 \mathrm{~K}$ range was detected, declining with time at $520 \mathrm{~K}$ (see Fig. 1(c)). Apparently under the specific reaction conditions only total oxidation is taking place on the oxide catalyst, which is consistent with the presence of traces of $\mathrm{CO}_{\mathrm{s}}$, the only species detected at $\mathrm{T}$
$>480-520 \mathrm{~K}$. Most likely the isothermal decline in the $\mathrm{CO}_{2}$ and $\mathrm{H}_{2} \mathrm{O}$ production at $520 \mathrm{~K}$ with time (about $15 \mathrm{~min}$ in our experiment) is due to partial reduction of the active $\mathrm{RuO}_{2}$ catalyst surface. The $\mathrm{Ru} 3 \mathrm{~d}_{5 / 2}$ and $\mathrm{O}$ 1s spectra evidence that further increase of $\mathrm{P}_{\mathrm{CH} 3 \mathrm{OH}}$ to get MMR of 0.25 leads to a very fast reduction of $\mathrm{RuO}_{2}$ into metallic $\mathrm{Ru}$ with some adsorbed oxygen. The two spectra in the top panel in Fig. 1(a and b) were measured $\sim 1$ (bottom) and 5 min after the $\mathrm{P}_{\mathrm{CH} \text { он }}$ increase. The attained catalyst steady-state under this new MMR condition is characterised by the appearance of a weak surface component in the $\mathrm{Ru} 3 \mathrm{~d}_{5 / 2}$ spectra at $279.5 \mathrm{eV}$, which indicates that the oxygen coverage drops below 0.5 ML [22], and according to the O 1s spectra these are the only ad-species present under steady conditions. The oxide reduction also changes the catalyst selectivity towards $\mathrm{CO}, \mathrm{H}_{2}$ and $\mathrm{H}_{2} \mathrm{O}$ products, as illustrated by the plots in Fig. 1(c). As can be expected, the dramatic change in the catalyst chemical state from oxide to metal affects the overall catalytic activity as well. Comparing the relative methanol consumption (attenuation mass 31 signal) we evaluated that the conversion of methanol on Ru oxide (MMR $=0.6)$ is $\sim 8 \%$, whereas on the metal catalyst (MMR $=0.25$ ) it grows to $\sim 29 \%$. Considering the higher $\mathrm{P}_{\mathrm{CH} 3 \mathrm{OH}}$ the total number of converted methanol molecules at $\mathrm{MMR}=0.25$ is about nine times higher.

Very similar reduction of the $\mathrm{RuO}_{2}$ to metallic $\mathrm{Ru}$, which catalyzes the same partial oxidation reaction to $\mathrm{CO}+$ $\mathrm{H}_{2} \mathrm{O}+\mathrm{H}_{2}$ was observed for MMR $<0.5$ up to mbar reactant partial pressures (see Fig. 2). However, the increase of the reagent pressures by several orders of magnitude leads to the following expected effects, manifested by the differences in the $\mathrm{Ru} 3 \mathrm{~d}_{5 / 2}$ and $\mathrm{O} 1 \mathrm{~s}$ spectra measured at the $10^{-6}$ and $10^{-1}$ mbar: (i) the $\mathrm{RuO}_{2}$ catalyst undergoes reduction to metallic $\mathrm{Ru}$ at lower temperature (already at $\sim 460 \mathrm{~K}$ ); (ii) the coverage of the $\mathrm{CH}_{3} \mathrm{O}_{\mathrm{s}}$ and $\mathrm{CH}_{2} \mathrm{O}_{\mathrm{s}}$ species on the oxide precatalyst increases, as judged by the higher intensity of the corresponding $\mathrm{O} 1 \mathrm{~s}$ components at $\sim 531.4$ and 532.2 $\mathrm{eV}$; (iii) in addition to oxygen the ad-layer at $520 \mathrm{~K}$ contains some $\mathrm{CO}_{\mathrm{s}}$, indicated by the second component at $531 \mathrm{eV}$ in the $\mathrm{O} 1 \mathrm{~s}$ spectra; (iv) the overall methanol conversion on the metallic Ru in the $10^{-1}$ range at $520 \mathrm{~K}$ and 
(a)

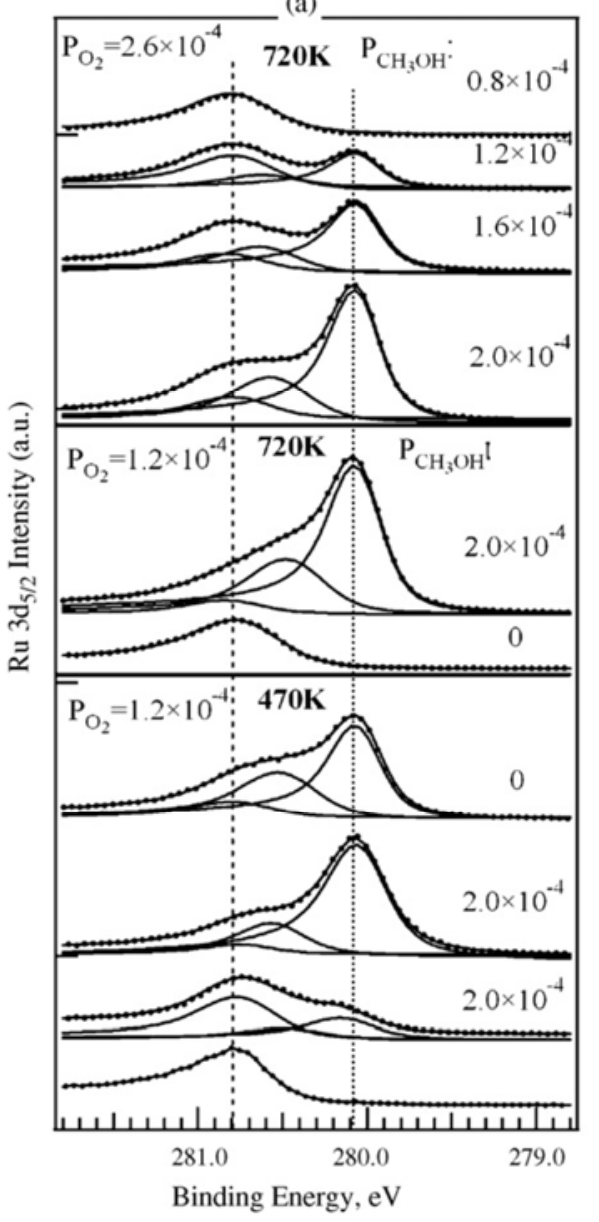

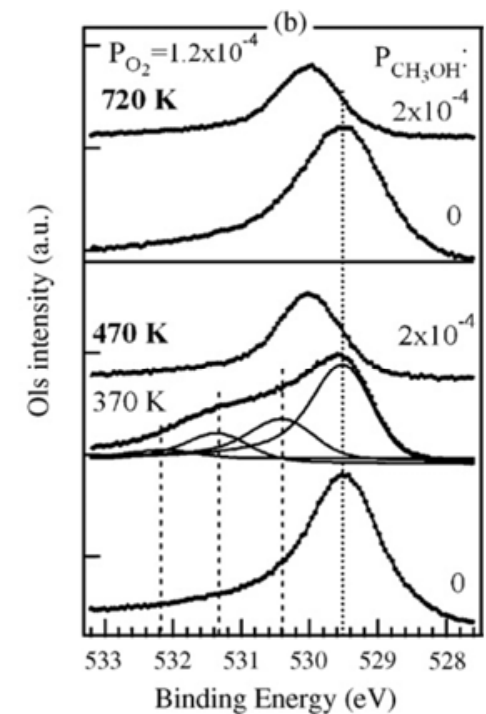

Binding Energy (eV)

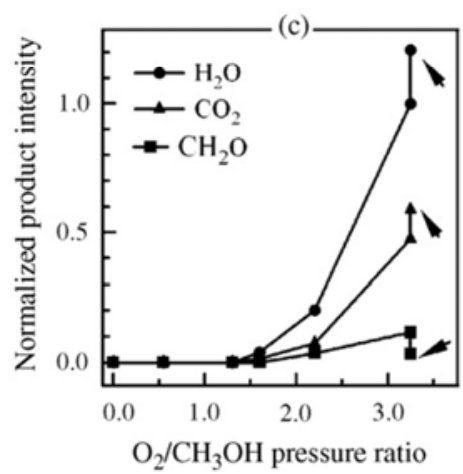

Fig. 3: (a) Ru 3d $\mathrm{d}_{5 / 2}$ spectra taken at $470 \mathrm{~K}$ (bottom panel) and $720 \mathrm{~K}$ (mid panel) showing the evolution of the Ru chemical state at constant $\mathrm{P}_{\mathrm{O} 2}=$ $1.2 \times 10^{-4}$ mbar for $\mathrm{P}_{\mathrm{CH} 3 \mathrm{OH}}=2.0 \times 10^{-4}(\mathrm{MMR}=0.6)$ and 0 mbar. The top panel shows the re-oxidation at $720 \mathrm{~K}$ with increasing MMR from 0.6 to 3.3 by varying the $\mathrm{P}_{\mathrm{O} 2}$ and $\mathrm{P}_{\mathrm{CH} 3 \mathrm{OH}}$, as indicated in the panel. (b) $\mathrm{O} 1 \mathrm{~s}$ spectra corresponding to the $\mathrm{Ru} 3 \mathrm{~d} 5 / 2$ spectra in the bottom and mid panel of (a). The dashed lines from left to right indicate the $\mathrm{O}$ 1s energy positions of $\mathrm{CH}_{2} \mathrm{O}_{\mathrm{s}}, \mathrm{CH}_{3} \mathrm{O}_{\mathrm{s}}$ and $\mathrm{OH}_{\mathrm{s}}$ or $\mathrm{CO}_{\mathrm{s}}$ and the dotted line indicates the oxide component. (c) Normalized mass spectra intensity of reaction products as a function of MMR at $720 \mathrm{~K}$ corresponding to the evolution of the $\mathrm{Ru} 3 \mathrm{~d}_{5 / 2}$ spectra in the top panel of (a), where PO2 is $2.6 \times 10^{-4} \mathrm{mbar}$ and $\mathrm{P}_{\mathrm{CH} 3 \mathrm{OH}}$ varies from 2.0 to $0.8 \times 10^{-4} \mathrm{mbar}$. The arrows indicate the change in the products yield after decreasing the temperature to $600 \mathrm{~K}$.

MMR $=0.3$ was $\sim 20 \%$, i.e. considering the $\mathrm{P}_{\mathrm{CH} 3 \mathrm{OH}}$ the number of the converted molecules is about 3 orders of magnitude higher compared to almost the same reaction pathway in the $10^{-6}$ range. At the $10^{-1}$ mbar pressure range we also detected very small production of $\mathrm{CH}_{2} \mathrm{O}$ at $520 \mathrm{~K}$ (see Fig. 2(c)), indicating that the competing reaction channel to formaldehyde production is opening at high temperatures.

Further-on, we will focus exclusively on the pressure dependence observed for MMR of 0.6, which was found to favour the $\mathrm{CH}_{2} \mathrm{O}$ production in the $10^{-1}$ mbar range, the highest pressures used in our experimental set-up. The $\mathrm{Ru}$ $3 d_{5 / 2}$ and $O 1 s$ spectra in Fig. 3 shows that in the $10^{-4}$ mbar range the $\mathrm{RuO}_{2}$ pre-catalyst undergoes partial reduction already at $470 \mathrm{~K}$. The $\mathrm{Ru} 3 \mathrm{~d}_{5 / 2}$ and $\mathrm{O} 1$ s spectra of the reduced state have the characteristic features of the RuOx 'surface oxide'. In accordance with our previous studies [14] the $\mathrm{RuO}_{2}$ state cannot be restored at $470 \mathrm{~K}$, but the amount of incorporated oxygen (reflected by the weight of
RuOx component) can significantly increase after switching-off the $\mathrm{CH}_{3} \mathrm{OH}$ flow. The oxide reduction becomes more efficient at higher temperatures $(720 \mathrm{~K})$, as evidenced by the spectra in the mid-panel in Fig. 3(a) and top panel in Fig. 3(b). For the $10^{-4}$ pressure range and $\mathrm{MMR}=0.6$ the only significant reaction at $470 \mathrm{~K}$ and $720 \mathrm{~K}$ was the oxide partial reduction to $\mathrm{RuOx}$ surface oxide state, which is apparently catalytically inactive at these low oxygen and methanol potentials.

The catalyst can be activated in the $10^{-4}$ range if it is reoxidised to $\mathrm{RuO}_{2}$, which takes place at temperatures above $600 \mathrm{~K}$ by increasing the MMR, as illustrated by the $\mathrm{Ru} 3 \mathrm{~d}_{5 / 2}$ spectra in the top panel in Fig. 3(a). However, as expected the steady $\mathrm{RuO}_{2}$ state at high MMR catalyzes the undesired total oxidation reaction to $\mathrm{H}_{2} \mathrm{O}+\mathrm{CO}_{2}$, as shown in Fig. 3(c). At MMR above two very low production of $\mathrm{CH}_{2} \mathrm{O}$ was also detected at $720 \mathrm{~K}$. Reducing stepwise the temperature the $\mathrm{H}_{2} \mathrm{O}$ and $\mathrm{CO}_{2}$ yields pass through a maximum at $600 \mathrm{~K}$, the $\mathrm{CH}_{2} \mathrm{O}$ yield drops almost to zero (see 

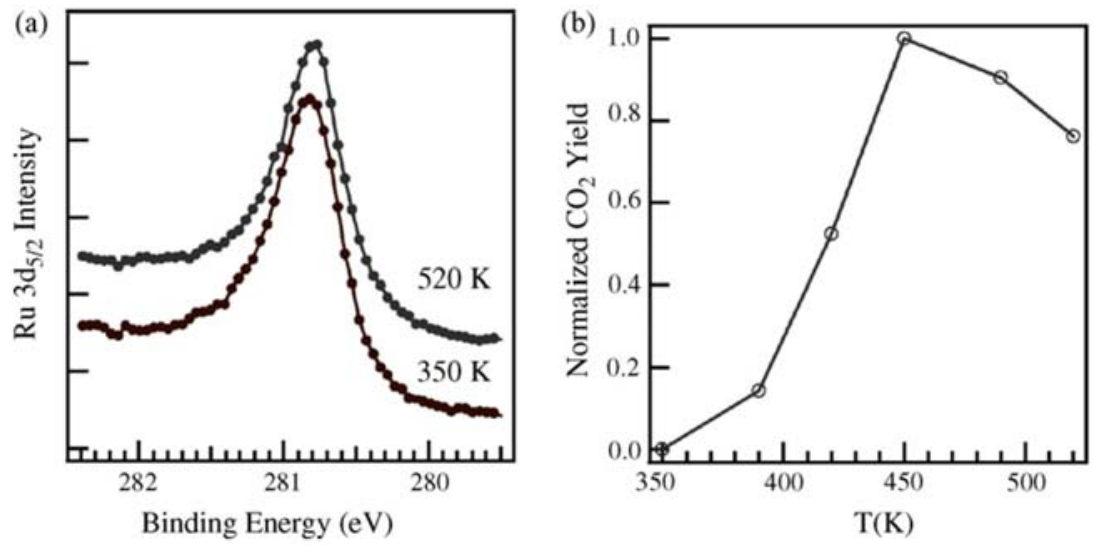

Fig. 4: (a) $\mathrm{Ru} 3 \mathrm{~d}_{5 / 2}$ spectra taken during the $\mathrm{CO}+\mathrm{O}_{2}$ reaction illustrating the preserved $\mathrm{RuO}_{2}$ state for reaction temperatures $350-520 \mathrm{~K}$. (b) Normalized $\mathrm{CO}_{2}$ mass spectra intensity as a function of temperature. $\mathrm{P}_{\mathrm{O} 2}=1.6 \times 10^{-4}$ and $\mathrm{P}_{\mathrm{CO}}=4.0 \times 10^{-4}$ mbar.
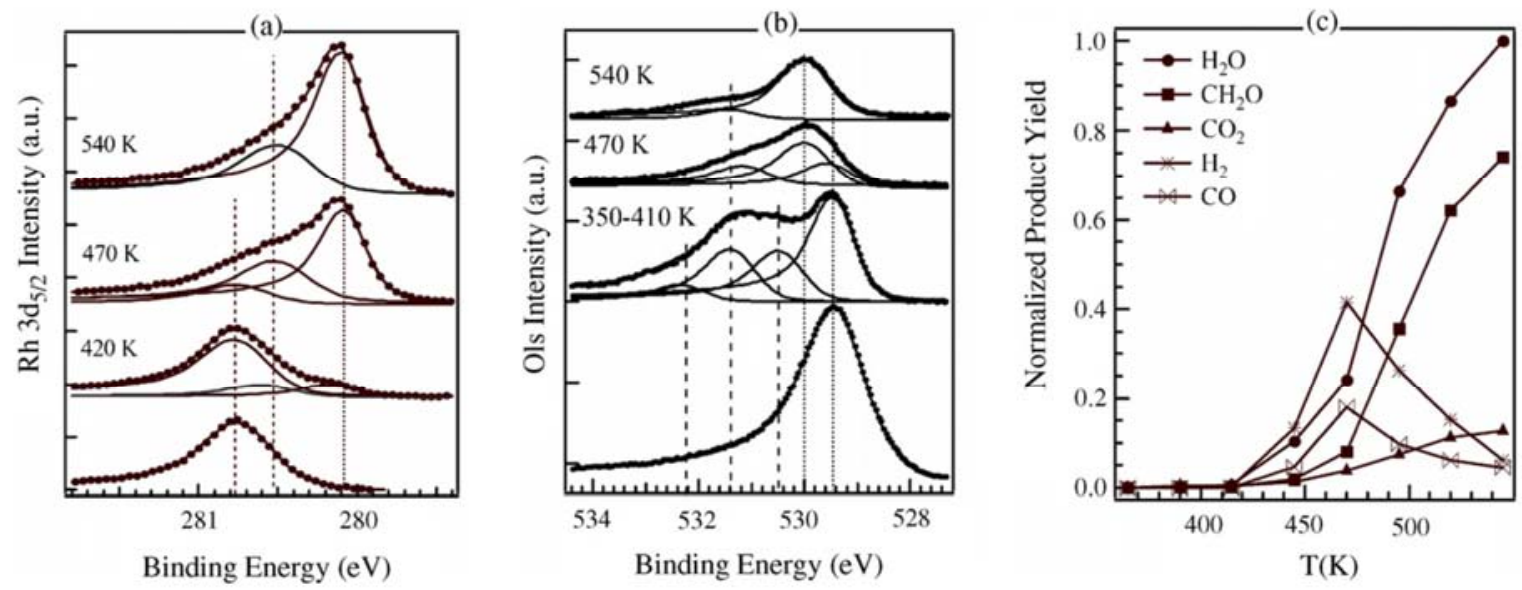

Fig. 5: Ru $3 d_{5 / 2}$ (a) and O 1s (b) spectra at different reaction temperatures for MMR $=0.6$ at $P_{\text {total }}=1.8 \times 10^{-1}$ mbar. In (a) and dashed lines indicate the $\mathrm{RuO}_{2}$ and $\mathrm{RuOx}$ components and the dotted line the bulk metallic Ru. In (b) the dashed lines from left to right indicate the O $1 \mathrm{~s}$ energy positions of $\mathrm{CH}_{2} \mathrm{O}_{\mathrm{s}}, \mathrm{CH}_{3} \mathrm{O}_{\mathrm{s}}$ and $\mathrm{OH}_{\mathrm{s}}$ or $\mathrm{CO}_{\mathrm{s}}$, and the dotted lines the adsorbed oxygen and oxide components. (c) Normalized mass spectra intensity of the reaction products.

the last points in Fig. 3(c) indicated by arrows) and the total methanol conversion increases from $41 \%$ at $720 \mathrm{~K}$ to $48 \%$ at $600 \mathrm{~K}$ and $\mathrm{MMR}=3.3$.

Comparison with the behaviour of the oxidised precatalyst during $\mathrm{CO}$ oxidation demonstrates the lower stability of the $\mathrm{RuO}_{2}$ state in $\mathrm{O}_{2}$ and $\mathrm{CH}_{3} \mathrm{OH}$ environment for the sameMMR in the $10^{-4}$ pressure range. This is due to the release of the very efficient reducing agent $\mathrm{H}$ during $\mathrm{CH}_{3} \mathrm{OH}$ decomposition. The $\mathrm{Ru} 3 \mathrm{~d}_{5 / 2}$ spectra in Fig. 4(a) for reaction temperature from 350 to $520 \mathrm{~K}$ show that the oxide catalyst resists reduction down to $\mathrm{O}_{2} / \mathrm{COMMR}$ of 0.4. As shown in Fig. 4(b) in this temperature range and MMR the $\mathrm{RuO}_{2}$ is very active for CO oxidation with a maximum $\mathrm{CO}_{2}$ yield at $450 \mathrm{~K}$. The decline in the $\mathrm{CO}_{2}$ yield at higher temperatures can tentatively be ascribed to the stability of adsorbed CO and/or cus-oxygen, in fair agreement with the calculated transition temperature, $450 \pm 50$ $\mathrm{K}$, for O-cus to O-bridge terminated $\mathrm{RuO}_{2}(110)$ surface at low pressures [30]. In the case of $\mathrm{CH}_{3} \mathrm{OH}$ for the same pressure range the $\mathrm{RuO}_{2}$ undergoes partial reduction already at $470 \mathrm{~K}$ even in $\mathrm{O}_{2}$-richer mixture. Since the $\mathrm{O} 1 \mathrm{~s}$ spectra indicated that the steady-state adspecies concentration at $\mathrm{T}>450 \mathrm{~K}$ is very low (i.e. adsorption-desorption processes of reactant and products is very fast) the different $\mathrm{T}, \mathrm{P}_{\mathrm{O} 2}$ stability ranges of $\mathrm{RuO}_{2}$ during $\mathrm{CO}$ and $\mathrm{CH}_{3} \mathrm{OH}$ oxidation is a direct illustration of the stronger effect of methanol chemical potential. This result holds for high pressures as well.

The results in Fig. 5(a and b), obtained for MMR = 0.6 in the $10^{-1}$ mbar pressure range, show that the oxidised pre-catalyst undergoes similar partial reduction to $\mathrm{RuOx}$ as in the $10^{-4}$ mbar range, but for these reactant's pressures and $\mathrm{T}>470 \mathrm{~K}$ the $\mathrm{RuOx}$ exhibits the desired catalyst selectivity to the reaction channel $\mathrm{CH}_{3} \mathrm{OH}+1 / 2 \mathrm{O}_{2}=\mathrm{CH}_{2} \mathrm{O}+$ $\mathrm{H}_{2} \mathrm{O}$. The catalyst performance with stepwise increasing temperatures, illustrated in Fig. 5(c) shows that in the temperature range of the on-going 
partial reduction (420-470 K) only the products of nonselective oxidative dehydrogenation, $\mathrm{H}_{2} \mathrm{O}, \mathrm{H}_{2}, \mathrm{CO}$ and $\mathrm{CO}_{2}$ are detected in the gas phase. After each temperature ramp their yields decayed fast ( 2 times) during the isothermal period and the plots in Fig. 5(c) shows the steady mass signal after the decay. The isothermal decay correlates with the changes in the catalyst surface, which according to the $\mathrm{Ru} 3 \mathrm{~d}_{5 / 2}$ and $\mathrm{O}$ 1s spectra in Fig. 5(a and b) involve partial reduction and desorption of the $\mathrm{CH}_{3} \mathrm{OH}$-related ad-species. The steady states for the 420-470 K range can be described as coexisting oxide and surface oxide regions with strongly decreased concentration of ad-species. Complete extinction of the oxide component was observed at $\sim 490 \mathrm{~K}$ and above this temperature the catalytically active state has only the spectral features of the RuOx surface oxide. Above $470 \mathrm{~K}$ the yields of the $\mathrm{CH}_{3} \mathrm{OH}$ dehydrogenation products $\left(\mathrm{H}_{2}\right.$ and CO) drop, whereas the $\mathrm{H}_{2} \mathrm{O}$ and $\mathrm{CO}_{2}$ yields continue growing. The desired product $\mathrm{CH}_{2} \mathrm{O}$ appears at $\sim 470 \mathrm{~K}$, the $\mathrm{H}_{2} \mathrm{O}$ and $\mathrm{CH}_{2} \mathrm{O}$ become the principle reaction products above $500 \mathrm{~K}$ and at $540 \mathrm{~K}$ the total methanol conversion reaches $28 \%$. The binding energy of the second weak component in the $\mathrm{O} 1 \mathrm{~s}$ spectra suggests that under steady conditions at $540 \mathrm{~K}$ only very small concentration of $\mathrm{CH}_{3} \mathrm{O}_{\mathrm{s}}$ species is present on the surface.

More light about the origin of the $\mathrm{H}_{2} \mathrm{O}, \mathrm{H}_{2}, \mathrm{CO}$ and $\mathrm{CO}_{2}$ yields at temperatures below $480 \mathrm{~K}$ is obtained from a 'TPD-type' experiment performed at the same reactant pressures, ramping continuously the temperature with $5 \%$ min and monitoring in situ the mass and $\mathrm{Ru} 3 \mathrm{~d}_{5 / 2}$ spectra. The XPS spectra confirm the conversion of the $\mathrm{RuO}_{2}$ to $\mathrm{RuOx}$ in the temperature range 420-500 K (Fig. 6(a)). The 'TPD'-like mass spectra in Fig. 6(b) can result from several competing reactions: recombination of $\mathrm{OH}_{\mathrm{s}}$ to $\mathrm{H}_{2} \mathrm{O}+\mathrm{H}_{\mathrm{s}}$, decomposition of the $\mathrm{CH}_{\mathrm{x}} \mathrm{O}_{\mathrm{s}}$ to $\mathrm{CO}_{\mathrm{s}}$ and $\mathrm{H}_{\mathrm{s}}$, and following secondary oxidation of fraction $\mathrm{CO}_{\mathrm{s}}$ and $\mathrm{H}_{\mathrm{s}}$ to $\mathrm{CO}_{2}$ and $\mathrm{H}_{2} \mathrm{O}$, the other $\mathrm{CO}_{\mathrm{s}}$ and $\mathrm{H}_{\mathrm{s}}$ fraction desorbing as $\mathrm{CO}$ and $\mathrm{H}_{2}$ in gas phase. The fact that the $\mathrm{CO}_{2}$ and $\mathrm{H}_{2} \mathrm{O}$ maxima are shifted to higher temperature with respect to that of $\mathrm{H}_{2}$ and $\mathrm{CO}$ ones indicates that $\mathrm{H}_{2} \mathrm{O}$ and significant amount of $\mathrm{CO}_{2}$ are formed via secondary reactions. Another competing viable pathway of $\mathrm{CO}_{2}+\mathrm{H}_{2} \mathrm{O}$ formation is via $\mathrm{CH}_{\mathrm{x}=2,3} \mathrm{O}_{\mathrm{s}}+$ $\mathrm{O}_{\mathrm{s}} \rightarrow \mathrm{H}-\mathrm{HCOO}_{\mathrm{s}}+(\mathrm{x}-1) \mathrm{H}_{\mathrm{s}} \rightarrow \mathrm{CO}_{2}+\mathrm{H}_{\mathrm{s}}$, where $\mathrm{H}_{\mathrm{s}}$ can desorbs as $\mathrm{H}_{2}$ or interacts with $\mathrm{OH}_{\mathrm{s}}$ and desorbs as $\mathrm{H}_{2} \mathrm{O}$. We cannot exclude contribution of this reaction to the mass spectra in Fig. 6, because the classical TPD experiments of methanol adsorption on $\mathrm{RuO}_{2}$ showed that some $\mathrm{CH}_{2} \mathrm{Os}$ species are present on the surface up to $450 \mathrm{~K}$ and can undergo dehydrogenation/oxidation to $\mathrm{HCOO}_{\mathrm{s}}$, according to the scheme above [26,31]. The 'TPD' results are also in excellent agreement with the $\mathrm{O}$ 1s spectra in Fig. 5, which clearly show that the components related to $\mathrm{CH}_{\mathrm{x}} \mathrm{O}_{\mathrm{s}}$ and $\mathrm{OH}_{\mathrm{s}}$ species are stable up to $410 \mathrm{~K}$ and only some traces of $\mathrm{CH}_{3} \mathrm{O}_{\mathrm{s}}$ remain at $540 \mathrm{~K}$. As for the experiments in the $10^{-4}$ pressure range, in the same temperature range the $\mathrm{RuO}_{2}$ catalyst undergoes partial reduction, because the reactive desorption of the $\mathrm{CH}_{\mathrm{x}} \mathrm{O}_{\mathrm{s}}$ and $\mathrm{OH}_{\mathrm{s}}$ species is accompanied by dynamic $\mathrm{CH}_{3} \mathrm{OH}$ re-adsorption from the gas phase, as confirmed by the continuous consumption of $\mathrm{CH}_{3} \mathrm{OH}$ in the gas phase. Apparently, under the actual reaction conditions the consumption of $\mathrm{O}_{s}$ via reactive oxidative desorption of $\mathrm{H}_{\mathrm{s}}$ and $\mathrm{CO}_{\mathrm{s}}$ cannot be compensated by the $\mathrm{O}_{2}$ adsorption and the oxide catalyst undergoes partial reduction. From the relative attenuation of the mass signal at 31 we evaluated that the conversion of methanol of non-selective oxidation at $\sim 470 \mathrm{~K}$ is $\sim 11 \%$, which almost coincides with the consumption measured during step-wise heating $\sim 10 \%$.

\section{Discussion}

The present results evidence a "pressure gap"' in the $\mathrm{CH}_{3} \mathrm{OH}$ selective oxidation, which has no simple explanation as in the case of $\mathrm{CO}$ oxidation on $\mathrm{Ru}(0001)$, where the activation of the metallic catalyst by oxidation is kinetically limited by the low oxygen potentials at $\mathrm{P}_{\mathrm{O} 2}<10^{-4}$ mbar. Here, starting with an oxide pre-catalyst we observed significant differences in the selectivity for $\mathrm{CH}_{3} \mathrm{OH}$ oxidation at low and high pressures. At given $\mathrm{T}$ the reactions depend on the relative methanol and oxygen chemical potentials, which control the catalyst chemical state and adsorbed reactant species. The products of the two non-selective reaction channels, full oxidation to $\mathrm{CO}_{2}+\mathrm{H}_{2} \mathrm{O}$ or partial oxidation to $\mathrm{CO}+\mathrm{H}_{2} \mathrm{O}+\mathrm{H}_{2}$ were observed in the whole pressure range considered in the present study, provided the partial reactants pressures and temperatures are properly chosen. Considering the methanol conversion even though measured under significantly different reaction we can conclude that the oxide exhibits high activity for nonselective full oxidation under reaction conditions preserving the $\mathrm{RuO}_{2}$ surface, high $\mathrm{P}_{\mathrm{O} 2}=\mathrm{P}_{\mathrm{CH} 3 \mathrm{OH}}$ ratio or lower $\mathrm{T}$ (see Figs. 1 and 3). Under this conditions desorption of a small fraction of $\mathrm{CH}_{2} \mathrm{O}_{\mathrm{s}}$ before converting to $\mathrm{HCOO}_{\mathrm{s}}$ or dehydrogenating to $\mathrm{CO}_{\mathrm{s}}$ (further-on $\mathrm{HCOO}_{\mathrm{s}}$ decomposes or $\mathrm{CO}_{\mathrm{s}}$ oxidises to $\mathrm{CO}_{2}$ ) can occur only at rather high $\mathrm{T}$ (720 $\mathrm{K}$ ), resulting in the traces of $\mathrm{CH}_{2} \mathrm{O}$ production. The drop of $\mathrm{CH}_{2} \mathrm{O}$ production to zero at $600 \mathrm{~K}$ (see Fig. 3) confirms such scenario. Lowering the high $\mathrm{P}_{\mathrm{O} 2}=\mathrm{P}_{\mathrm{CH} 3 \mathrm{OH}}$ ratio affects the stability of the $\mathrm{RuO}_{2}$ pre-catalyst structure and depending on the actual pressure ratio $\mathrm{RuO}_{2}$ undergoes partial reduction to a RuOx surface oxide or full reduction to metallic Ru. The metallic Ru state catalyzes effectively only non-selective partial oxidation to $\mathrm{CO}, \mathrm{H}_{2} \mathrm{O}$ and $\mathrm{H}_{2}$ in the whole pressure range under consideration.

The intriguing result of the present study is that even if the conditions of the low-pressure experiments are selected to attain the same catalytically active chemical state as at high pressures not necessarily the desired reaction is catalyzed at low potentials of the reactants. This concerns the RuOx surface oxide state, which becomes active only in the $10^{-1}$ mbar range catalyzing the selective oxidation to $\mathrm{CH}_{2} \mathrm{O}$ at $\mathrm{T}>450 \mathrm{~K}$. As evidenced by the $\mathrm{Ru} 3 \mathrm{~d}_{5 / 2}$ and $\mathrm{O} 1 \mathrm{~s}$ spectra in Fig. 5 starting from a $\mathrm{RuO}_{2}$ pre-catalyst the partial reduction to the RuOx surface oxide precedes the onset of selective $\mathrm{CH}_{2} \mathrm{O}$ production. The fits of the $\mathrm{Ru} 3 \mathrm{~d}_{5 / 2}$ spectra in Figs. 5 and 6 clearly show that both states, $\mathrm{RuO}_{2}$ and $\mathrm{RuOx}$, coexist in a wide temperature range, which points 

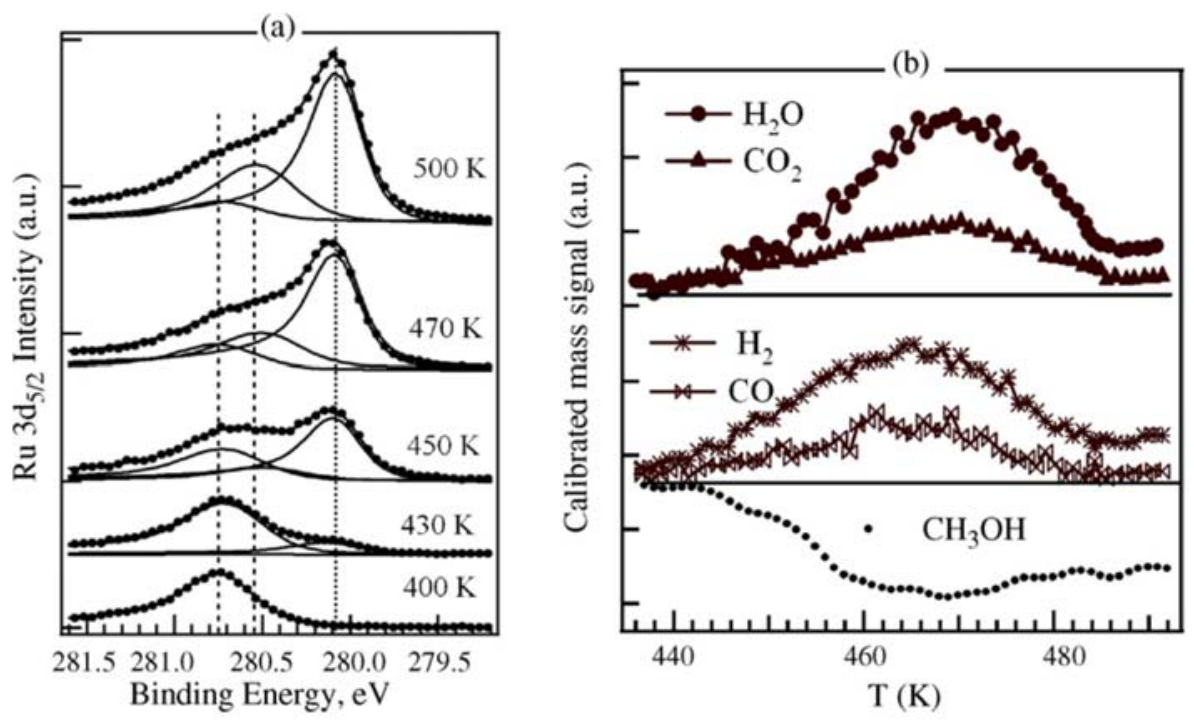

Fig. 6: Evolution of the Ru $3 \mathrm{~d}_{5 / 2}$ spectra (a) and normalized mass spectra intensity of reaction products (b) monitored during continuous increase of temperature by $5 \mathrm{~K} / \mathrm{min}$ for MMR $=0.6$ at $\mathrm{P}_{\text {total }}=1.2 \times 10^{-1}$ mbar. The dotted line in (b) shows the attenuation of mass 31, a measure of $\mathrm{CH}_{3} \mathrm{OH}$ conversion.

towards a patchy surface. Above $500 \mathrm{~K}$ the $\mathrm{RuO}_{2}$ component is practically absent and the weight of the RuOxrelated component characterises the catalytically active state as a thin few layer surface oxide with poorly defined stoichiometry and structure.

A plausible reason for the observed pressure gap in RuOx activity to $\mathrm{CH}_{2} \mathrm{O}$ formation should be kinetic limitations to get the optimal coverage of the reacting species with specific adsorption configurations favouring the $\mathrm{CH}_{2} \mathrm{O}$ production. Undoubtedly, the $\mathrm{RuO}_{2}$ reduction process involving a massive mass transport and restructuring can result in built-up of strain and/or surface roughening and the degree of such dynamic morphological changes may generate configurations with specific reactivity, related to a specific T, P space. This may also determine the critical amount of incorporated oxygen, which selectively activates the catalyst surface to build the optimum surface coverage of the reacting species for the desired reaction channel. Consequently, the high catalyst selectivity should be observed only in a narrow $\mathrm{T}, \mathrm{P}_{\mathrm{O} 2}, \mathrm{P}_{\mathrm{CH} 3 \mathrm{OH}}$ space providing the most favourable energetics of interlinked processes of adsorption, desorption, surface diffusion andsurface reactions. For the reaction system under consideration the crucial intermediate steps relevant to $\mathrm{CH} 2 \mathrm{O}$ production are the following:

$$
\begin{aligned}
& \mathrm{CH}_{3} \mathrm{OH}+\mathrm{O}_{\mathrm{s}} \rightarrow \mathrm{CH}_{3} \mathrm{O}_{\mathrm{s}}+\mathrm{OH}_{\mathrm{s}} \\
& \mathrm{CH}_{3} \mathrm{O}_{\mathrm{s}} \rightarrow \mathrm{CH}_{2} \mathrm{O}_{\mathrm{s}}+\mathrm{Hs} \rightarrow \mathrm{CH}_{2} \mathrm{O}_{\text {gas }}+\mathrm{H}_{\mathrm{s}} \\
& \mathrm{CH}_{2} \mathrm{O}_{\mathrm{s}}+\mathrm{O}_{\mathrm{s}} \rightarrow \mathrm{HCOO}_{\mathrm{s}}+\mathrm{H}_{\mathrm{s}} \rightarrow \mathrm{CO}_{2}+\mathrm{H}_{\mathrm{s}} \\
& \mathrm{CH}_{2} \mathrm{O}_{\mathrm{s}}+\mathrm{O}_{\mathrm{s}} \rightarrow \mathrm{CO}_{\mathrm{s}}+\mathrm{H}_{\mathrm{s}} \text { and } / \mathrm{orOH}_{\mathrm{s}}
\end{aligned}
$$

In our experiments reaction (2) is slower than (1), which sustains some low concentration of $\mathrm{CH}_{3} \mathrm{O}_{\mathrm{s}}$, the only ad-species detected under steady conditions at $540 \mathrm{~K}$. Apparently the catalytically active state should promote reaction (2) with immediate $\mathrm{CH}_{2} \mathrm{O}_{\mathrm{s}}$ desorption. If the $\mathrm{CH}_{2} \mathrm{O}_{\mathrm{s}}$ lifetime on the surface is long enough it can undergo further oxidationdehydrogenation reactions, types (3) and (4), which favour $\mathrm{CO}_{2}$ or $\mathrm{CO}$ pathways. The most plausible explanation is to correlate the selective $\mathrm{CH}_{2} \mathrm{O}$ production to the thermal stability of $\mathrm{CH}_{2} \mathrm{O}_{\mathrm{s}}$. $\mathrm{CH}_{2} \mathrm{O}_{\mathrm{s}}$ can be bonded to the surface in two configurations, single-bonded trough the $\mathrm{O}$ lone pair orbital, or double-bonded via $\mathrm{C}$ and $\mathrm{O}$ atoms through carbonyl porbital, the latter being the more stable one [19]. The less stable single-bonded configuration is the preferred one in the presence of oxygen. Therefore one can easily envision that optimal amount of oxygen present at the surface can critically affect the product selectivity not by direct participation in the reaction but via modification of the surface electronic properties and destabilizing adsorbate-adsorbate interactions, which tune the kinetics of $\mathrm{CH}_{2} \mathrm{O}$ desorption.

\section{Conclusions}

In situ XPS and mass spectrometry shed light on the sensitivity of competing methanol oxidation pathways to the 'pressure gap', starting with and Ru oxide pre-catalyst and varying the partial reactants pressure from UHV to mbar range. We found that the three main oxidation channels, namely total oxidation to $\mathrm{CO}_{2}+\mathrm{H}_{2} \mathrm{O}$, partial oxidation to $\mathrm{CO}+\mathrm{H}_{2} \mathrm{O}+\mathrm{H}_{2}$ and partial oxidation to $\mathrm{CH}_{2} \mathrm{O}+$ $\mathrm{H}_{2} \mathrm{O}$, require completely different catalyst chemical states, which develop only under specific $\mathrm{T}, \mathrm{P}_{\mathrm{O} 2}, \mathrm{P}_{\mathrm{CH} 3 \mathrm{OH}}$ reaction conditions. For all oxygen/ methanol partial pressure ratios used in the present study only the formaldehyde production 
is hindered at low pressures, with exception of some traces detected at $\mathrm{T}>600 \mathrm{~K}$.

In the whole pressure range under consideration the $\mathrm{RuO}_{2}$ phase is found to be stable only in the $\mathrm{O}_{2}$-rich mixtures and catalyzes the total oxidation to $\mathrm{CO}_{2}+\mathrm{H}_{2} \mathrm{O}$. In $\mathrm{CH}_{3} \mathrm{OH}$-rich mixtures and $\mathrm{T}>420 \mathrm{~K}$ the $\mathrm{RuO}_{2}$ undergoes reduction even at pressures as low as $10^{-6} \mathrm{mbar}$ and depending on the reactants partial pressures the reduction can terminate at the transient $\mathrm{RuOx}$ surface oxide state. The metallic Ru catalyzes the partial oxidation reaction $\mathrm{CO}+$ $\mathrm{H}_{2} \mathrm{O}+\mathrm{H}_{2}$, which is also pressure insensible. The $\mathrm{RuOx}$ state turned out to catalyse preferentially the formaldehyde production. Although this state can be formed at low pressures it is activated only at $10^{-1}$ mbar pressures. Such 'pressure gap' in the selectivity was tentatively ascribed to the

\section{References}

[1] P. Mars, D.W. van Krevelen, Chem. Eng. Sci. 3 (1954) 41.

[2] J.A. Labinger, K.C. Ott, Cat. Lett. 4 (1990) 245.

[3] H. Bluhm, M. Hävecker, A. Knop-Gericke, E. Kleimenov, R. Schlögl, D. Teschner, V.I. Bukhtiyarov, D.F. Ogletree, M. Salmeron, J. Phys. Chem. B 108 (2004) 14340.

[4] L. Zhou, S. Gunther, D. Moszynski, R. Imbihl, J. Catal. 235 (2005) 359.

[5] C.I. Carlisle, T. Fujimoto,W.S. Sim, D.A. King, Surf. Sci. 470 (2000) 15.

[6] K. Reuter, in: I. Heiz, H. Hakkinen, U. Landman (Eds.), Nanocatalysis: Principles, Methods, Case Studies, Springer-Verlag, 2005.

[7] C. Stampfl, Catal. Today 105 (2005) 17.

[8] A. Soon, M. Todorova, B. Delley, C. Stampfl, Phys. Rev. B 73 (2006) 165424.

[9] H. Over, Y.D. Kim, A.P. Seitsonen, E. Lundgren, M. Schmid, P. Varga, A. Morgante, G. Ertl, Science 287 (2000) 1474.

[10] H. Over,M. Muhler, Prog. Surf. Sci. 72 (2003) 3 (and references therein).

[11] A. Böttcher, H. Niehus, J. Chem. Phys. 110 (1999) 3186; A. Böttcher, H. Niehus, Phys. Rev. B 60 (1999) 14396.

[12] R. Blume, H. Niehus, H. Conrad, A. Böttcher, J. Phys. Chem. B 108 (2004) 14332.

[13] A. Böttcher, U. Starke, H. Conrad, R. Blume, L. Gregoratti, B. Kaulich, A. Barinov, M. Kiskinova, J. Chem. Phys. 117 (2002) 8104.

[14] R. Blume, H. Niehus, H. Conrad, A. Bo“ttcher, L. Aballe, L. Gregoratti, A. Barinov, M. Kiskinova, J. Phys. Chem. B 109 (2005) 14052.

[15] R. Blume, M. Hävecker, S. Zafeiratos, D. Teschner, E. Kleimenov, A. Knop-Gericke, R. Schlögl, A. Barinov, P. Dudin, M. Kiskinova, J. Catal. 239 (2006) 354. correlation between oxygen coverage and the lifetime of the $\mathrm{CH}_{2} \mathrm{O}$ intermediate at the surface, the optimal conditions being determined by a narrow $\mathrm{T}, \mathrm{P}_{\mathrm{O} 2}, \mathrm{P}_{\mathrm{CH} 3 \mathrm{OH}}$ space.

\section{Acknowledgements}

M. Kiskinova thanks AvH foundation for the Award to pursue research in FHI-Berlin in 2004-2005. P. Dudin acknowledges the financial support under Contract No. NMP3-CT-2003-505670 (NANO2). The BESSY staff is acknowledged for their continuous support to perform the present measurement.
[16] W. Vogel, N. Alonso-Vante, J. Catal. 232 (2005) 395.

[17] H. Schulenberg, M. Hilgendorff, I. Dorbandt, J. Radnik, P. Bogdanoff, C. Fiechter, M. Bron, H. Tributsch, J. Power Sources 155 (2006) 47 (and references therein).

[18] M.K. Weldon, C.M. Friend, Chem. Rev. 96 (1996) 1391.

[19] M. Mavrikakis, M. Barteau, J. Mol. Catal. A: Chem. 131 (1998) 135 (and references therein).

[20] H. Liu, E. Iglesia, J. Chem. Phys. B 109 (2005) 2155.

[21] D.F. Ogletree, H. Bluhm, C. Lebedev, C.S. Fadley, Z. Hussain, M. Salmeron, Rev. Sci. Instrum. 73 (2002) 3872. S. Lizzit, A. Baraldi, A. Groso, K. Reuter, M.V. Ganduglia-Pirovano, C. Stampfl, M. Scheffler, M. Stichler, C. Keller, W. Würth, D. Menzel, Phys. Rev. B 63 (2001) 205419.

[22] M.P. Seah, Surf. Interf. Anal. 9 (1986) 85.

[23] NIST database, http://srdata.nist.gov/xps/.

[24] H. Over, A.P. Seitsonen, E. Lundgren, M.Wiklund, J.N. Andersen, Chem. Phys. Lett. 342 (2001) 467.

[25] M. Knapp, et al., in preparation (private communications).

[26] S. Günther, L. Zhou, M. Havecker, A. Knop-Gericke, E. Kleimenov, R. Schlögl, R. Imbihl, J. Chem. Phys. 125 (2006) 11479 (and references therein).

[27] A. Schiffer, P. Jacob, D. Menzel, Surf. Sci. 389 (1997) 116.

[28] G. Rotaris, A. Baraldi, G. Comelli, M. Kiskinova, R. Rosei, Surf. Sci. 359 (1996) 1.

[29] [K. Reuter, M. Scheffler, Phys. Rev. B 65 (2001) 35406.

[30] H. Madhavaram, H. Idriss, S. Wendt, Y.D. Kim, M. Knapp, H. Over, J. Amann, E. Löffer, M. Muhler, J. Catal. 202 (2001) 296. 